\title{
Using seawater iron isotopes to characterize the physicochemical speciation and scavenging rates of dissolved iron: Southern East Pacific Rise hydrothermal plume
}

\author{
JANELLE STEFFEN ${ }^{1}$, BRENT SUMMERS ${ }^{2}$, TIM \\ CONWAY $^{2}$, CHRISTOPHER GERMAN ${ }^{3}$, ROBERT M. \\ SHERRELL $^{4}$ AND JESSICA FITZSIMMONS ${ }^{1}$ \\ ${ }^{1}$ Texas A\&M University \\ ${ }^{2}$ University of South Florida \\ ${ }^{3}$ Wood Hole Oceanographic Institution \\ ${ }^{4}$ Rutgers University \\ Presenting Author: janellemsteffen@tamu.edu
}

The bioavailability and scavenging fate of dissolved iron $(\mathrm{dFe})$ in the ocean is dependent on its physicochemical speciation, yet there are no analytical methods that reveal the general character of marine $\mathrm{dFe}$, especially basic differentiation of organicallycomplexed $\mathrm{Fe}$ from inorganic nanoparticulate phases. Here, we propose that $\mathrm{Fe}$ isotopes can be used to infer this speciation, as long as the system meets certain assumptions. We demonstrate this using a case study of the Southern East Pacific Rise (SEPR) non-buoyant hydrothermal plume at $15^{\circ} \mathrm{S}$. We objectively assign $\mathrm{Fe}$ isotope signatures for each of three $\mathrm{dFe}$ species that are present in the hydrothermal plume: background organic $\mathrm{dFe}$ ligand (FeL) complexes, hydrothermal organic dFe-ligand complexes, and $\mathrm{Fe}$ oxyhydroxide nanoparticles. We then apply these isotope signatures to an isotope mass balance model, which also includes the soluble and colloidal Fe concentrations, to reveal the complete physico-chemical speciation of $\mathrm{dFe}$ in this plume.

We show that hydrothermally-sourced Fe-oxyhydroxide nanoparticles dominate $\mathrm{dFe}$ near the ridge-axis but are rapidly removed down-plume (net residence times: $<10$ y soluble, $<20$ y colloidal). In contrast, hydrothermally-sourced dFe-ligand complexes are present only as soluble-sized species near the ridge-axis, followed by aggregation/exchange into larger colloidal ligand complexes that begin to dominate $\mathrm{dFe}$ concentrations down-plume (residence time 10-60 y). Colloidalsized ligand-stabilized $\mathrm{dFe}$ persists farthest among all hydrothermal $\mathrm{dFe}$ species. Overall, these results point to relatively rapid hydrothermal $\mathrm{dFe}$ removal rates and suggest that short transport pathways from ridge sources to the surface ocean, such as occurs in the Southern Ocean, are essential for hydrothermal influence on phytoplankton growth and the global carbon cycle. 